\title{
PEMANFAATAN CITRA LANDSAT 8 OLI UNTUK MENGKAJI KEBUTUHAN RUANG TERBUKA HIJAU BERDASARKAN KEBUTUHAN OKSIGEN DI KOTA SEMARANG
}

\section{TESIS}

\section{Untuk Memenuhi Sebagian Persyaratan \\ Untuk Mencapai Derajat S2}

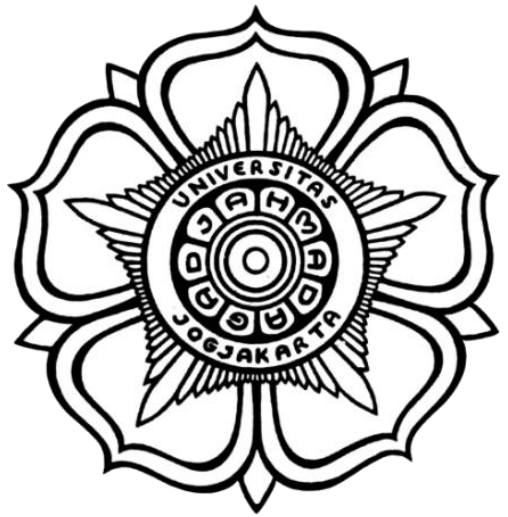

Disusun Oleh:

ANIFA WIDIYANTARI

NIM. 12/339747/PGE/01000

\author{
PROGRAM STUDI PENGINDERAAN JAUH \\ PROGRAM PASCASARJANA \\ FAKULTAS GEOGRAFI \\ UNIVERSITAS GADJAH MADA \\ YOGYAKARTA \\ 2018
}




\title{
PEMANFAATAN CITRA LANDSAT 8 OLI UNTUK MENGKAJI KEBUTUHAN RUANG TERBUKA HIJAU BERDASARKAN KEBUTUHAN OKSIGEN DI KOTA SEMARANG
}

\author{
Anifa Widiyantari
}

12/339747/PGE/01000

\section{INTISARI}

Kota Semarang merupakan salah satu kota besar di Indonesia dan merupakan Ibu Kota Provinsi Jawa Tengah. Kota Semarang terbagi menjadi 16 kecamatan dengan luas wilayah seluas $373,7 \mathrm{~km}^{2}$. Jumlah penduduk pada tahun 2010 adalah 1.527 .433 jiwa dan bertambah menjadi 1.595.187 jiwa pada tahun 2015 dengan laju pertumbuhan penduduk di Kota Semarang pada tahun 2015 sebesar $0,59 \%$. Jumlah penduduk yang meningkat akan diiringi dengan peningkatan kebutuhan RTH. Tujuan dari penelitian ini adalah untuk mengestimasi kebutuhan RTH berdasarkan kebutuhan oksigen tahun 2017, tahun 2020 dan tahun 2030, menggunakan data Penginderaan Jauh Citra Landsat 8 OLI Tahun 2015; mengkaji ketersediaan RTH Kota Semarang terhadap kebutuhan oksigen tahun tahun 2017, tahun 2020 dan tahun 2030; serta mengkaji arahan pengembangan RTH di Kota Semarang.

Kebutuhan RTH berdasarkan pendekatan kebutuhan oksigen di Kota Semarang diketahui dari perbandingan kondisi keseluruhan luasan RTH yang didapat menggunakan metode klasifikasi maximum likelihood pengolahan Citra Landsat 8 OLI Tahun 2015 untuk mendapatkan RTH Eksisting dan kebutuhannya oksigen menggunakan metode Gerrarkis.

Kebutuhan oksigen di Kota Semarang semakin meningkat tetapi di lain pihak penyedia oksigen RTH keseluruhan semakin berkurang. Akurasi penutup lahan RTH Eksisting yang diperoleh memberikan hasil yang baik, yaitu sekitar $>85 . \%$. Hasil perhitungan Luas RTH dengan metode Gerrarkis berdasarkan kebutuhan oksigen penduduk, kendaraan bermotor dan industri, diketahui jumlah kebutuhan Luas RTH Kota Semarang pada tahun 2017 adalah 44.283,41 Ha, sementara luas RTH eksisting di Kota Semarang saat ini adalah 10.724.03 Ha. Untuk mendapatkan luas RTH Kota Semarang yang ideal sesai metode Gerrarkis, maka Kota Semarang harus menambah kawasan RTH seluas atau sebesar 34.099,45 Ha. Hasil Estimasi kebutuhan RTH di Kota Semarang untuk tahun 2020 adalah sebesar 51.585,38 Ha dan di tahun 2030 meningkat menjadi 74.334,18 Ha. Arahan pengembangan RTH di Kota Semarang diklasifikasikan menjadi dua kelas yaitu diprioritaskan untuk menambah RTH dan diprioritaskan untuk tidak menambah RTH. RTH eksisting di Kecamatan Gunungpati seluas 2.040,91 Ha masih ditutupi RTH, dengan kebutuhan RTH 1.949,30 Ha dimana arahan pengembangan RTH diproritaskan tidak menambah RTH. Begitupula dengan Kecamatan Banyumanik yang memiliki RTH eksisting seluas 3.691,95 Ha dengan kebutuhan RTH seluas 3.207,93 Ha arahan pengembangan RTH juga diprioritaskan tidak menambah RTH. Sementara 14 Kecamatan lainny di Kota Semarang kekurangan RTH, sehingga memerlukan penambahan RTH.

Kata kunci : RTH, Citra Landsat 8 OLI, Klasifikasi Maximum Likelihood, Kebutuhan Oksigen, Metode Gerrarkis 


\title{
UTILIZATION OF LANDSAT 8 OLI IMAGES FOR STUDYING GREEN OPEN SPACE BASED ON OXYGEN NEEDS IN SEMARANG CITY
}

\author{
Anifa Widiyantari \\ 12/339747/PGE/01000
}

\begin{abstract}
Semarang city is one of the big cities in Indonesia and is the capital of Central Java. Semarang City is divided into 16 districts with an area of $373.7 \mathrm{~km} 2$. The population in 2010 is $1,527,433$ people and increased to $1,595,187$ people by 2015 with population growth rate in Semarang City in 2015 of 0,59\%. The increased population will be accompanied by an increase in the needs green open space. The purpose of this research is to estimate the needs rth based on the ned for oxygen demand in 2017, 2020 and 2030, using Remote Sensing Data of OLI Landsat 8 Year 2015; Assessing the availability of Green Open Scace of Semarang City to oxygen demand in 2017, 2020 and 2030; And review the direction of RTH development in Semarang City.
\end{abstract}

The need for green space based on the approach of oxygen demand in Semarang City is known from the comparison of the overall Green Open Scace area conditions obtained using the maximum likelihood classification method of Landsat 8 OLI Year 2015 to obtain the Existing Green Open Scace and its oxygen needs using Gerrarchic method.

The need for oxygen in the city of Semarang is increasing, but on the other hand the suppliers of Green Open Scace oxygen overall are decreasing. Accuracy of land cover Green Open Scace Existing obtained gives good results, which is approximately $>85 . \%$. The calculation of the area of green open space with Gerrarkis method based on the population oxygen requirement, motor vehicles and industry, it is known that the total area of RTH of Semarang City in 2017 is 48,173.16 Ha, while the existing Green Open Scace area in Semarang city is 10,724.03 Ha. To get the ideal Green Open Scace area of Semarang City following Gerrarkis method, Semarang City must add Green Open Scace area of 37,449.13\% or equal. The Result of Estimation of RTH requirement in Semarang City for the year 2020 is equal to 51,585,38 $\mathrm{Ha}$ and in year 2030 increase become 74.334,18 Ha. The direction of RTH development in Semarang City is classified into two classes that are prioritized to increase the RTH and prioritized not to increase the RTH. Existing green space in Gunungpati sub-district of 2,040.91 Ha is still covered by RTH, with the requirement of RTH 1,949.30 Ha where RTH development directed priority does not increase RTH. Similarly with Banyumanik District which has an existing RTH of 3,691.95 Ha with the needs of RTH of 3.207.93 Ha of RTH development direction is also prioritized not to increase RTH. While the other 14 sub-districts in Semarang City lack of green open space, so it requires the addition of green open space.

Key Words: Green Open Scace, Remote Sensing Data of OLI Landsat 8, maximum likelihood classification method, oxygen requirement Gerrarkis method. 


\section{DAFTAR ISI}

HALAMAN JUDUL ...............................................................................

HALAMAN PENGESAHAN ..................................................................... ii

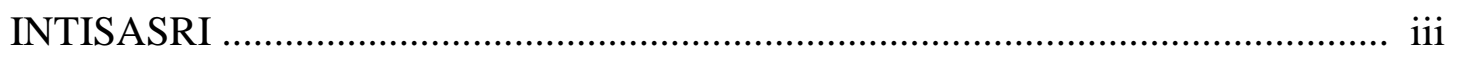

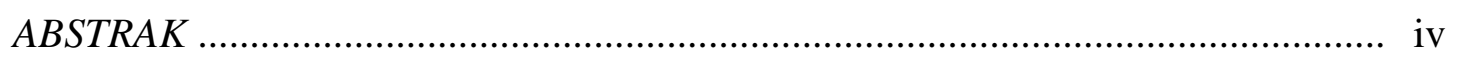

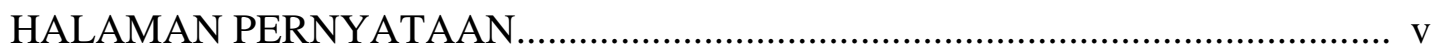

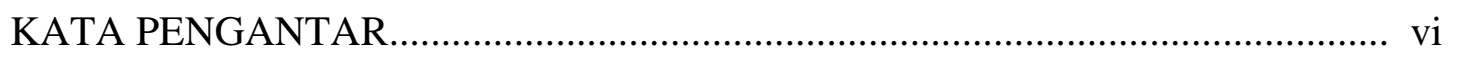

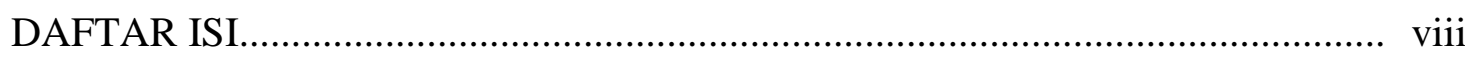

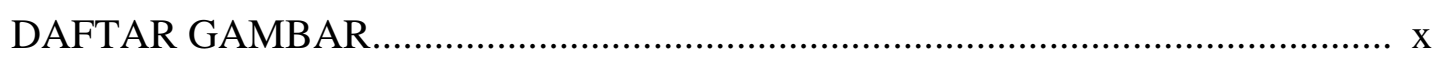

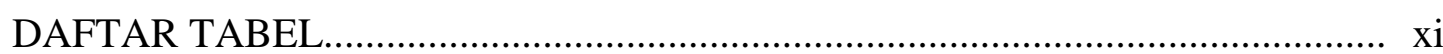

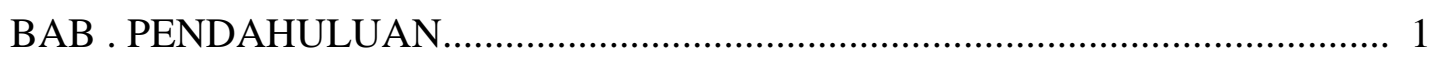

1.1 Latar Belakang................................................................................ 1

1.2 Perumusan Masalah............................................................................. 4

1.3 Tujuan Penelitian .................................................................................... 6

1.4 Manfaat Penelitian ............................................................................... 7

1.5 Keaslian Penelitian ........................................................................... 7

1.6 Wilayah Penelitian ......................................................................... 15

BAB II. TINJAUAN PUSTAKA................................................................... 17

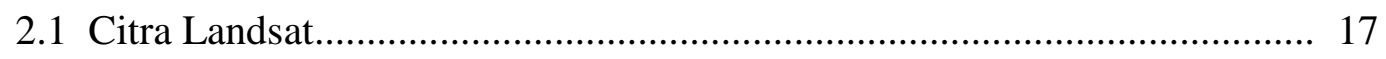

2.2 Klasifikasi Multispektral: Maximum Likelihood .................................... 21

2.3 Penutup Lahan dan Penggunaan Lahan...................................................... 23

2.4 Uji Akurasi Hasil Klasifikasi .............................................................. 25

2.5 Ruang Terbuka Hijau (RTH) Kota.................................................... 27

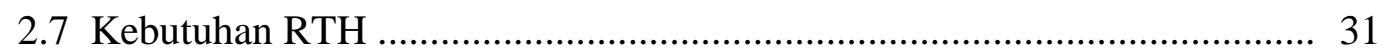

2.7 Kebutuhan Oksigen ............................................................................. 32

2.8 Pemenuhan Kebutuhan Oksigen Penduduk.............................................. 34

2.9 Kerangka Pemikiran ............................................................................ 35

BAB III. METODE PENELITIAN ............................................................... 38

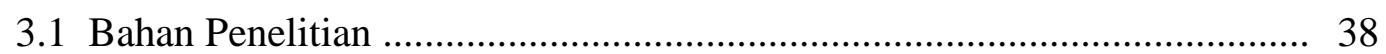

3.2 Peralatan Penelitian .................................................................................. 39

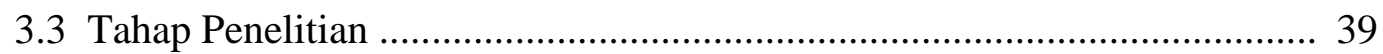

3.3.1 Persiapan Penelitian.................................................................... 39

3.3.2 Pengumpulan Data ..................................................................... 39

3.3.3 Estimasi Kebutuhan RTH Berdasarkan Kebutuhan Oksigen ............. 40

3.3.3.1 RTH Existing ............................................................... 40

3.3.3.2 Analisis Kebutuhan RTH Berdasarkan Kebutuhan Oksigen ...... 45

3.3.4. Penentuan Arahan Pengembangan RTH .......................................... 49

3.4 Diagram Alir Penelitian...................................................................... 49 


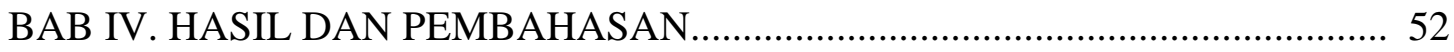

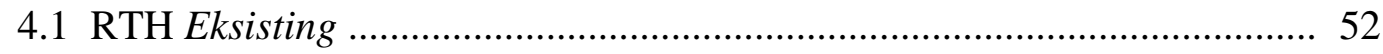

4.1.1 Koreksi Geometrik .................................................................. 52

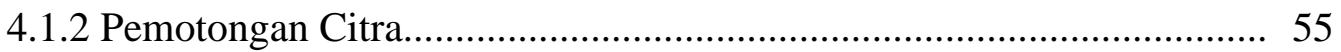

4.1.3 Penentuan Skema Klasifikasi............................................................. 56

4.1.4 Pembuatan Daerah Contoh (Training Area) ...................................... 56

4.1.6 Klasifikasi Maximum Likelihood ........................................................ 59

4.2 Analisis Kebutuhan RTH Berdasarkan Kebutuhan Oksigen ..................... 60

4.2.1 Estimasi Kebutuhan Oksigen Penduduk............................................. 60

4.2.2 Estimasi Kebutuhan Oksigen Kendaraan Bermotor............................. 64

4.2.3 Estimasi Kebutuhan Oksigen Industri............................................... 68

4.3 Analisis Kebutuhan Luas Ruang Terbuka Hijau ....................................... 70

4.4 Arahan Pengembangan RTH di Kota Semarang ...................................... 73

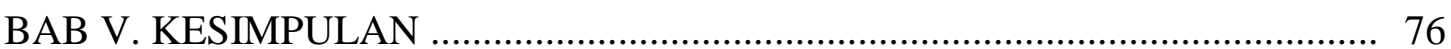

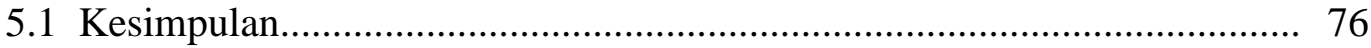

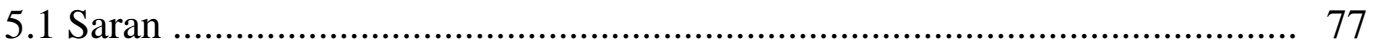

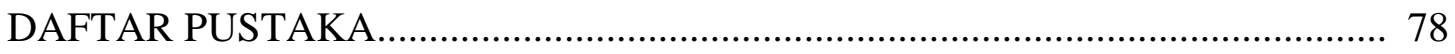

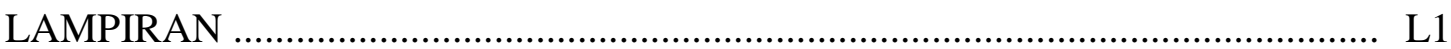




\section{DAFTAR GAMBAR}

Gambar 2.1 Desain Sensor Landsat-8, OLI (kiri) dan TIRS (kanan) (Sumber: NASA, 2014) ................................ 19

Gambar 2.2 Kerangka Pemikiran......................................... 37

Gambar 3.1 Diagram Alir Penelitian ................................... 51

Gambar 4.1 Sebaran GCP Koreksi Geometrik Landsat 8 OLI Tahun 2015..... 53

Gambar 4.2 Nilai RMS dan GCP List Citra Landsat 8 OLI Tahun 2015....... 54

Gambar 4.3 Pemotongan Landsat 8 OLI Tahun 2015 berdasar batas administras kecamatan terluar Kota Semarang ............................ 55

Gambar 4.4 (a) Citra Landsat 8 OLI 432 Tahun 2015 (True Colour) daerah kajian, (b) Citra Landsat 8 OLI Tahun 2015 komposit 543 (False Colour) daerah kajian Kota Semarang

Gambar 4.5 Citra Landsat 8 OLI 432 Tahun 2015 komposit 543 dengan contoh kenampakan visual tiap kelas penutup lahan.................... 58

Gambar 4.6 Contoh kenampakan (a) objek RTH vegetasi Hutan (koordinat: 49 M 434487mT, 9222948mU); (b) Objek RTH vegetasi kebun (campuran) (koordinat: $49 \mathrm{M} 438702 \mathrm{mT}, 778383 \mathrm{mU})$ 


\section{DAFTAR TABEL}

Tabel 1.1 Jumlah Penduduk Kota Semarang Tahun 2010 - 2015............... 2

Tabel 1.2 Jumlah kendaraan di Kota Semarang Tahun $2005-2014 \ldots \ldots \ldots \ldots \ldots .5$

Tabel 1.3 Keaslian Penelitian.............................................. 12

Tabel 1.4 Luas Wilayah per Kecamatan di Kota Semarang.................... 16

Tabel 2.1 Panjang gelombang pada citra Landsat 5 TM..................... 17

Tabel 2.2 Panjang gelombang tiap band pada citra Landsat 7 ETM $+\ldots \ldots \ldots \ldots . \quad 18$

Tabel 2.3 Panjang gelombang tiap band pada citra Landsat 8 OLI \& TIRS..... 19

Tabel 2.4 Skema Klasifikasi Penutup LahaContoh Perhitungan Confusion Matrix ........................................................... 27

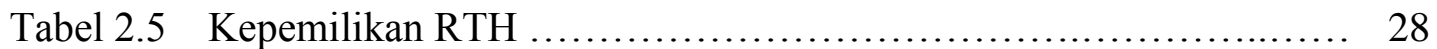

Tabel 2.6 Penyedia RTH Berdasarkan Jumlah Penduduk....................... 31

Tabel.2.7 Kebutuhan Oksigen Berdasarkan Setiap Konsumen Oksigen.......... 33

Tabel.3.1 Skema Klasifikasi Penutup Lahan SNI 7645-1 2014 _................ 41

Tabel.3.2 Klasifikasi Kendaraan Bermotor Menurut Penggunaan ............... 48

Tabel 3.3 Kebutuhan Oksigen Berdasarkan Jenis Kendaraan Bermotor ......... 49

Tabel 4.1 Proyeksi Jumlah Penduduk Kota Semarang (Desember 2016 - 2030) 61

Tabel 4.2 Estimasi kebutuhan oksigen penduduk tahun $2017 \ldots \ldots \ldots \ldots \ldots \ldots \ldots . \ldots 2$

Tabel 4.3 Kebutuhan oksigen berdasarkan jenis kendaraan bermotor............. 66

Tabel 4.4 Estimasi Kebutuhan Oksigen Kendaraan Bermotor Per Kecamatan

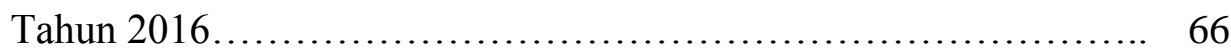

Tabel 4.5 Estimasi Kebutuhan Oksigen Industri Per Kecamatan Tahun

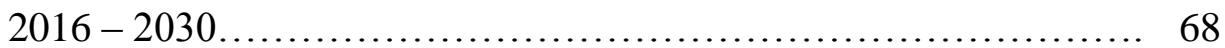

Tabel 4.6 Estimasi Kebutuhan Oksigen untuk masing - masing variabel....... 69

Tabel 4.7 Estimasi Kebutuhan RTHberdasarkan Kebutuhan oksigen............. 70

Tabel 4.8 Arahan pengembangan RTH di kota Semarang .................. 71 


\section{DAFTAR PUSTAKA}

Peraturan Menteri Dalam Negeri Nomor 1, 2007. Penataan Ruang Terbuka Hijau Kawasan Perkotaan. Jakarta

Peraturan Menteri Pekerjaan Umum Nomor 5, 2008. Pedoman Penyediaan Pemanfaatan Ruang Terbuka Hijau Di Kawasan Perkotaan. Jakarta

Undang - Undang Republik Indonesia, Nomor 26, 2007. Penataan Ruang. Jakarta

Peraturan Daerah Kota Semarang, Nomor 7, 2010. Penataan Ruang. Semarang.

NASA (National Aeronautics and Space Administration), 2014. Landsat Science NASA. [Online] Available at: http://landsat.gsfc.nasa.gov/

Badan Pusat Statistik Kota Semarang. 2010. Kota Semarang Dalam Angka 2009. Semarang: BPS dan Bappeda.

Badan Perencanaan Pembangunan Daerah Kota Semarang, 2006, Laporan Antara Penyusuan Rencana Tata Ruang Terbuka Hijau (RTRH) Kota Semarang. Semarang.

Badan Perencanaan Pembangunan Daerah Kota Semarang. 2000. Rencana Tata Ruang Wilayah Kota Padang Tahun 2000-2010.Semarang.

Caspersen, H., Konijnendijk, C. C., Olafson, A. S. 2006. Green Space Planning and Land Use: An Assesment of Urban Regional and Green Structure Planning in Greater Copenhagen. Danish Journal of Geography. 106 (2). 7-20.

Congalton, R.G., Green, K., 2008. Assessing the Accuracy of Remotely Sensed Data, Principles and Practices, seconded. Taylor \& Francis Group. CRC Press.

Danoedoro, P., 1996. Pengolahan Citra Digital : Teori dan Aplikasinya Dalam Bidang Penginderaan Jauh. Yogyakarta: Fakultas Geografi, Universitas Gadjah Mada.

Danoedoro, P., 2012. Pengantar Penginderaan Jauh Digital.Yogyakarta:Fakultas Geografi, Universitas Gadjah Mada.

Dian, Q.F., 2007. Evaluasi Jalur Hijau Kota Yogyakarta Tinjauan Fungsi Ekolosis, Etetis Dan Sosiokultural. Yogyakarta: Tesis - Universitas Gadjah Mada.

Djurdjani, 1999. Pengolahan Citra Digital. Yogyakarta: Fakultas Teknik Universitas Gadjah Mada,

Emmanuel, R. 2005. Thermal Comfort Implications of Urbanization in a Warmhumid City: The Colombo Metropolitan Region (CMR), Sri Lanka. J Building and Evironment. 40: 1591- 1601. 
Gasman. 1984. Peranan Tumbuh-Tumbuhan dalam Menghasilkan Oksigen. Jakarta: Harian A.B.

Ginting, F. A., 2006. Pemodelan Spasial Penentuan Agihan Optimal RTH Kota Berdasarkan Basis Data Spasial Lingkungan Kota Memanfaatkan SIG, studi kasus Yogyakarta. Yogyakarta: Tesis - Universitas Gadjah Mada.

Fandeli,C., Kaharuddin dan Mukhlison, 2004. Perhutanan Kota. Yogyakarta: Fakultas Kehutanan Universitas Gadjah Mada.

Harintaka, 2010, Penginderaan Jauh, Yogyakarta: Fakultas Teknik Universitas Gadjah Mada.

Hartini, Sri., 2008. Analisis Konversi Ruang Terbuka Hijau Ke Penggunaan Perumahan di Kecamatan Tembalang Kota Semarang. Yogyakarta: Tesis - Universitas Gadjah Mada.

Heryuka, M. Sindy., 2013. Kebijakan Pengelolaan RTH Perkotaan (Studi Kasus Pemerintah Kota Surabaya). Yogyakarta: Tesis - Universitas Gadjah Mada.

Hidayat, I. W., 2010. The Ecological Role of Trees and Their Interactions in Forming the Microclimate Amenity of Environment. J Bumi Lestari. 10(2):182-190.

Indrawati, Like., 2009. Klasifikasi Pohon Keputusan untuk Kajian Perubahan Penggunaan Lahan Kota Semarang Menggunakan Citra Landsat TM/ETM+. Yogyakarta: Tesis - Universitas Gadjah Mada.

Irwan, Z. Djamal., 2005. Tantangan Lingkungan Lansekap Hutan Kota. Yogyakarta.

Jensen, J., 1996, Introductionary Digital Image Processing : A Remote Sensing Perspective, London: Prentice Hall

Jensen, J., 2005. Introductury Digital Image Processing (Third Edition). London: Prentice Hall.

Lillesand, T.M. and Kiefer, R.W. 1994. Remote Sensing and Image Interpretation. $2^{\text {nd }}$. Edition. John Wiley and Sons, Inc.Canada.

Martopo. S., Fandeli, C., Herlian A., dan Purwanto, A., 1995. Pengaruh RTH kota terhadap kondisi lingkungan sekitarnya di kodya Yogyakarta (laporan penelitian), Yogyakarta: Lembaga Penelitian - Universitas Gadjah Mada.

Mas, J.F., Ramirez, I.,1996. Comparison of land use classifications obtained by visual interpretation and digital processing. ITC Journal, 3(4), 278-283. 
Muis, A. B., 2005. Analisis Kebutuhan Ruang Terbuka Hijau berdasarkan Kebutuhan Oksigen dan Air di Kota Depok Propinsi Jawa Barat. Bogor: Tesis Departemen Arsitektur Lanskap Fakultas Pertanian, Fakultas pertanian, Institut Pertanian Bogor.

Ohira., 2012. Analisis Citra Alos AVNIR-2 Dan SIG untuk Pengembangan RTH. Yogyakarta: Tesis - Universitas Gadjah Mada. Yogyakarta

Pancawati, Juwarin., 2010. Analisis Kebutuhan Ruang Terbuka Hijau di Kota Tangerang. Bogor: Tesis - Institut Pertanian Bogor.

Purbowaseso, B., 1995. Penginderaan Jauh Terapan. Jakarta: UI-Press.

Purnomohadi., 2006. Ruang Terbuka Hijau Sebagai Unsur Utama Tata Ruang Kota. Jakarta: Direktorat Jenderal Penataan Ruang Departemen Pekerjaan Umum..

Samudra, I.S., 2007. Kajian Kemampuan Metode Jaringan Syaraf Tiruan Untuk Klasifikasi Penutup Lahan Dengan Menggunakan Citra Aster. Yogyakarta: Tesis - Universitas Gadjah Mada..

Shahidan MF, Shariff MKM., Jones P, Shalleh E, Abdullah AM. 2010. A Comparison of Mesua ferrea L. And Hurra crepitans L. For Shade Creation and Radiation Modification in Improving Thermal Comfort. $J$ Landscape and Urban Planning 97:168-181.

Sidiq, Wahid. B.N. 2013. Pemanfaatan Penginderaan Jauh dan SIG untuk Evaluasi Dan Arahan Pengembangan RTH di Kota Semarang. Yogyakarta: Tesis Universitas Gadjah Mada.

Sutanto., 1994. Penginderaan jauh, Jilid 2, Yogyakarta: Gadjah Mada University Press.

Taufik, Fazlul., 2009. Kajian Kebutuhan Dan Konversi Ruang Terbuka Hijau Di Kota Padang. Yogyakarta: Tesis - Universitas Gadjah Mada..

Wahyudi. 2009. Ketersediaan Alokasi Ruang Terbuka Hijau Kota Pada Ordo Kota I Kabupaten Kudus. Semarang: Tesis - Universitas Diponegoro 